\title{
ANÁLISE DAS CONDIÇÕES DE ACESSIBILIDADE DE PROJETO EM EXECUÇÃO DE RESTAURANTE UNIVERSITÁRIO
}

\author{
RODRIGUES, Lucas Barbosa da Silveira (1); \\ NUNES, Michele Chagas (2); \\ ANDRADE, Isabela Fernandes (3) \\ (1)Universidade Federal de Pelotas, Graduando. \\ e-mail: lucassilveirarodrigues@hotmail.com \\ (2) Universidade Católica de Pelotas, Graduanda. \\ e-mail: michele.cn@gmail.com \\ (3) Universidade Federal de Pelotas, Doutora. \\ e-mail: acessiara@gmail.com
}

\begin{abstract}
RESUMO
Trabalho de pesquisa, com estrutura avaliativa das condições de acessibilidade do projeto em execução do restaurante universitário da Universidade Federal de Pelotas - Campus Anglo. Conta com avaliação técnica do projeto em questão, questionário com usuários dos atuais restaurantes universitários e entrevista com grupos focais de estudantes da Universidade. Parte deste material encontra-se em andamento, porém, conta com todos os elementos de perícia e soluções para as problemáticas encontradas. Os resultados demonstram que algumas questões podem ser alteradas durante a execução do projeto para que todas as pessoas, independentemente de suas capacidades e/ou limitações, usufruam da edificação.
\end{abstract}

Palavras chave: acessibilidade; inclusão; restaurante universitário.

\begin{abstract}
Research work, with evaluation structure of the accessibility conditions of the project in execution of the university restaurant of the Federal University of Pelotas - Campus Anglo. It has a technical evaluation of the project in question, a questionnaire with users of current university restaurants and an interview with focus groups of University students. Part of this material is in progress, however, it has all the elements of expertise and solutions to the problems encountered. The results demonstrate that some issues can be changed during project execution so that all people, regardless of their capabilities and / or limitations, enjoy the building.
\end{abstract}

Keywords: accessibility; inclusion; university restaurant.

\section{INTRODUÇÃO}

Localizado no Porto de Pelotas/RS, no Campus Anglo da Universidade Federal de Pelotas, onde também situa-se o gabinete da reitoria, a maior concentração de pró-reitorias e de setores administrativos, o prédio do futuro Restaurante Universitário $(R U)$ encontra-se em 


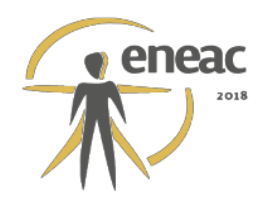

obras desde outubro de 2017, com conclusão prevista para julho de 2018. Trata-se de um projeto com área de intervenção superior a $1.160 \mathrm{~m}^{2}$, com o objetivo de viabilizar a fruição dos serviços de alimentação da Universidade, cuja licitação totaliza o montante de $R \$$ 1.658.799,00.

Em decorrência da existência de muitas salas de aula, laboratórios e setores administrativos, o campus comporta numerosa quantidade de discentes e servidores, recebendo acesso dinâmico de pessoas, já que trata-se de um campus que tem funcionamento em turno integral. Devido a esse fluxo de pessoas, a demanda por um espaço para refeições, como almoço e jantar, é muito intensa já que o $R U$ mais próximo encontra-se no centro da cidade. Tal deslocamento torna-se inviável para muitos alunos devido às dificuldades e transtornos na simples locomoção, sem sequer considerar existência ou inexistência de deficiência. Ainda sem avaliar aspectos ergonômicos e de acessibilidade no interior dos prédios, há entraves que dificultam acesso e uso dos serviços do $\mathrm{RU}$, como por exemplo, o superlotamento dos ônibus e o curto intervalo de tempo para a ida e volta, nos casos de alunos e servidores que precisam retornar ao campus para atividades em turno integral.

Atualmente, há três restaurantes universitários em funcionamento, porém, os serviços de alimentação configuram uma grande problemática em diversos aspectos, seja no de logística, acessibilidade, ergonomia ou até mesmo habitabilidade. Casos como bancos quebrados, iluminação e ventilação insuficiente, falta de equipamentos e mobiliários adequados para pessoas com deficiência ou mobilidade reduzida, inexistência de atendimento preferencial ou especializado, dificuldades de acesso devido à impossibilidade de deslocamento ou até mesmo inexistência de identificação visual que configure e identifique os prédios como Restaurantes Universitários, são exemplos de inadequações no uso e acesso de tais serviços.

Visando ampliar a capacidade, qualificar o atendimento e melhorar a distribuição geográfica da oferta de alimentação, foi aberto processo de licitação que está permitindo a construção do novo restaurante. O mesmo é objeto de estudo deste trabalho justamente para que sejam feitas, a partir de perícias técnicas, intervenções sobre o que foi insuficiente ou equivocadamente proposto. Também se desenvolveu uma pesquisa integrada de satisfação dos usuários, em termos de ergonomia e acessibilidade, para identificar as maiores problemáticas recorrentes. Trata-se de um projeto de pesquisa "intervencionista" porque tem cunho de perícia e correção técnicas, embasadas em bibliografias e normas inerentes ao assunto. Além disso, constitui-se de uma pesquisa de satisfação denominada "integrada" porque conta com um questionário geral e entrevista focal com pessoas com restrição ou deficiência vinculados à Universidade.

Considerando o panorama histórico da inclusão da acessibilidade nos ambientes e processos, também devido à liberdade de expressão proporcionada pela internet e à legislação vigente que obriga órgãos públicos e empresas a planejarem espaços e processos com inclusão, na atualidade é muito mais fácil dar visibilidade e voz às demandas dessas pessoas e também às carências encontradas nos ambientes construídos. A Constituição Federal, no seu Art. 208ํㅡ, Inciso III, estabelece que o dever do Estado com a educação será efetivado mediante garantia de atendimento educacional especializado aos portadores de deficiência, preferencialmente na rede regular de ensino.

\section{OBJETIVO}

Sabendo-se que um restaurante universitário está intimamente atrelado a manutenção da vida universitária, bem como representa um espaço de trocas de informação e convívio entre alunos e servidores, é natural que seja considerado um espaço estritamente vinculado 
à educação, isto é, configura obrigação do Estado para com a promoção de um espaço acessível. Devido a essa obrigação, este trabalho dá seguimento nas pesquisas e propostas para que todos os resultados encontrados sejam convertidos em resoluções de melhoramento nos espaços da UFPel, já que, conforme a Lei Federal no 8.666 de 21 de Junho (1993), os contratos de licitação poderão ser alterados, com as devidas justificativas e unilateralmente pela Administração, quando houver modificação do projeto ou das especificações para melhor adequação técnica aos seus objetivos. Ou seja, mesmo com as obras do RU em execução, ainda é possível adaptar o projeto no caso de inadequações através de propostas de aditivos ao valor licitado originalmente.

O objetivo deste trabalho é avaliar as condições de acessibilidade propostas em projeto e, identificados equívocos, propor soluções de melhorias que possam ser implementadas a partir de termos aditivos ao contrato. A partir disso, cria-se um material de propostas intervencionistas e também reforça-se o compromisso em dar visibilidade às demandas dos alunos e servidores com deficiência desta Universidade, abrindo-se um espaço inédito de participação e inclusão.

Resultados de perícia técnica e propostas de intervenções estão conclusas, porém, resultados de pesquisa e coleta de dados são parciais, já que essas etapas ainda encontram-se em desenvolvimento. Após a finalização da pesquisa, todo o material será disponibilizado abertamente para consulta pública e apresentado no evento em questão.

\section{REFERENCIAL TEÓRICO}

Qual é o significado da acessibilidade? Para se compreender esse conceito é importante conhecer a história mais recente desse movimento, que pode ter sua origem datada no início dos anos 60, quando surge, na área da arquitetura, tanto nos EUA como na Europa, o conceito de projetos livres de barreiras, focado principalmente na deficiência física, em particular nos problemas de circulação que afetam as pessoas usuárias de cadeiras de rodas. (MAZZONI; TORRES; OLIVEIRA; BINS ELY; ALVES, 2001). Entretanto, é importante frisar que eliminar barreiras físicas não é suficiente para promover pleno acesso, já que parte da sociedade está sob condições díspares, situação que conceitua o termo diversidade.

Promover a acessibilidade no ambiente construído é proporcionar condições de mobilidade, com autonomia e segurança, eliminando as barreiras arquitetônicas e urbanísticas nas cidades (edifícios, meios de transporte e de comunicação). Isto constitui um direito universal resultante de conquistas sociais importantes, que reforçam o conceito de cidadania. Um espaço construído, quando acessível a todos, é capaz de oferecer oportunidades igualitárias a seus usuários, promovendo a inclusão social. (ARAÚJO; CÂNDIDO; LEITE, 2009). Ou seja, considerando os conceitos de inclusão e acessibilidade, percebe-se que têm estreito vínculo como os conceitos de urbanidade e civilidade, fundamentais para o funcionamento de uma sociedade diversificada. Isto é, através do respeito, da empatia, é natural que modelos acessíveis sejam implementados para a promoção da inclusão.

Considerando acesso à informação, acesso à cultura, acesso à educação, por exemplo, é possível identificar que o simples fato de conseguir chegar a um local não é o mesmo que participar das atividades de forma autônoma e igualitária. Entendendo a importância da linguagem, da comunicação, da promoção da autonomia e independência, da disposição de um espaço onde todos possam participar, estabelecendo-se equidade, planejando de forma holística, é como a engenharia e a arquitetura têm seus papéis bem desenvolvidos na sociedade, já que estão alicerçadas nas concepções de bom planejamento.

Sabendo-se que não há uma padronização ou um modelo universal e generalista de ser humano, entendendo que as características psíquicas, morfológicas, físicas e pessoais 


\section{ieneac}

podem ser muito díspares, é necessário que todo planejamento de espaços físicos acessíveis, bem como dos processos e serviços que tal ambiente promoverá, seja concebido e proposto pensando no desenho universal (DU). Essa terminologia de DU é denominada, de acordo com a Associação Brasileira de Normas Técnicas (ABNT), através da NBR 9050 (2015), como concepção de produtos, ambientes, programas e serviços a serem utilizados por todas as pessoas, sem necessidade de adaptação ou projeto específico, incluindo os recursos de tecnologia assistiva.

A importância de tal planejamento torna-se visivelmente fundamental ao avaliar dados estatísticos, pois, considerando apenas o contexto da realidade brasileira, de acordo com o Censo (2016) do Instituto Brasileiro de Geografia e Estatística (IBGE), o Brasil possui 45 milhões de Pessoas com deficiência, sendo que, segundo os dados da Relação Anual de Informações Sociais (2015), mais de 400 mil trabalham formalmente.

Pode-se considerar que, quando um único aluno for impedido de entrar numa biblioteca ou numa sala de aula pela simples existência de uma barreira física, a função educadora de uma universidade estará sendo colocada imediatamente em xeque. (DUARTE; COHEN, 2004). Ou seja, como uma Universidade poderá cumprir seu papel social sem a garantia de que todos possam ter acesso aos seus espaços, às suas atividades e à cultura? Seria sensato limitar o conhecimento? Obviamente, sem acessibilidade não há máxima eficiência na educação, e é quando tem-se demandas nas instituições que todo o sistema sofre pressões para atendê-las, já que algo estará sendo solicitado. Isto é, quando garante-se as vagas por cotas nas universidades, é quando se torna possível identificar problemáticas, é quando expressa-se a necessidade de atualizações e melhoramentos. Porém, garantir espaço, seja ele físico ou nas matrículas por cotas, não é sinônimo de garantia de acessibilidade, já que esta é um termo de amplas abrangências.

Para orientar as ações de avaliação e fiscalização dos edifícios públicos, estabelece-se uma classificação dos Componentes da Acessibilidade Espacial em quatro categorias: orientação espacial, comunicação, deslocamento e uso. Cada componente é constituído por um conjunto de diretrizes que definem características espaciais de forma a permitir a acessibilidade aos edifícios públicos e minimizar possíveis restrições espaciais. É importante salientar que a acessibilidade espacial depende do atendimento desses componentes em sua totalidade e que, dependendo das condições dos usuários e de suas necessidades, basta o não-cumprimento de um deles para que todos os demais sejam comprometidos. (DISCHINGER, BINS ELY E PIARDI, 2012. Adaptado.).

Atendendo ao componente denominado "orientação espacial", o usuário deverá ser capaz de ter entendimento de onde se localiza ou então ser capaz de obter informações espaciais do local onde deseja ir. A partir do componente caracterizado "comunicação", entende-se a importância da comunicação para o contato com tecnologias da informação ou então como forma de relação interpessoal. Não existirá inclusão sem participação, e não existirá participação ou sequer organização se não houver comunicação compreensível para todos. A categoria "deslocamento" é, deveras, o componente mais facilmente identificável. É o componente que, basicamente, deve garantir o efetivo direito de ir e vir, o direito de ter acesso físico aos locais públicos, o direito de deslocar-se seguramente e da forma mais autônoma possível. Quanto ao componente "uso", é o componente que deve atender, universalmente, às peculiaridades e necessidades dos usuários quanto a mobiliários, aparelhos e dispositivos de uso específico tais como aparelhos sanitários, utilização de superfícies, aparelhos eletrônicos, vagas especiais para pessoas com deficiências e barras de apoio, por exemplo. 


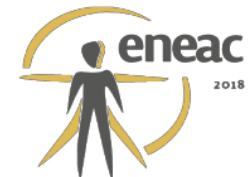

\section{MÉTODOS E TÉCNICAS}

\subsection{Norteadores de avaliação}

Tendo em vista a análise do projeto, em termos de identificação de problemáticas, bem como as possíveis intervenções cabíveis, este trabalho se norteia, fundamentalmente, de acordo com a norma NBR 9050 (ABNT, 2015), que trata sobre Acessibilidade a edificações, mobiliário, espaços e equipamentos urbanos. Também são agregadas às consultas a norma NBR 16.537 (ABNT, 2016), a qual trata sobre Acessibilidade - Sinalização tátil no piso Diretrizes para elaboração de projetos e instalação; bem como com as bibliografias Dimensionamento Humano Para Espaços Interiores (PANERO; ZELNIK, 2008) e Arte de Projetar em Arquitetura (NEUFERT, 2013.). Sob caráter de perícia, para montagem de laudo técnico-acadêmico, utiliza-se a produção Promovendo acessibilidade espacial nos edifícios públicos (DISCHINGER, BINS ELY E PIARDI, 2012).

\subsection{Técnicas de análise do ambiente construído}

A análise do ambiente construído segue um roteiro que conta com: questionário geral de satisfação acerca dos atuais ambientes construídos; pesquisa focal com pessoas com deficiência/restrição/mobilidade reduzida; perícia projetual com embasamento nas bibliografias supracitadas; elaboração de laudo técnico-acadêmico; proposta de intervenção em planta e maquete eletrônica; disponibilização do material para a Universidade, para fins de correção no projeto ou incremento de aditivos no contrato de licitação para execução da obra.

\section{RESULTADOS}

\subsection{Questionário geral de satisfação dos usuários}

Foi disponibilizado on-line um questionário geral de satisfação dos usuários, o qual coletou dados de extrema relevância para a observância de aspectos físicos dos mesmos e aspectos específicos do ambiente construído. Tais dados, embora sejam referentes aos espaços atuais, dão base mais sólida para a tomada de decisões nas propostas intervencionistas do restaurante em construção. É uma forma de identificar as maiores problemáticas da atualidade para não mais serem problemáticas no futuro espaço. 0 questionário contou com 134 respostas, tendo um período de vigência de 22/12/2018 a 22/01/2018. Seguem os questionamentos e resultados:

Tabela 1. Qual sua faixa etária?

\begin{tabular}{|c|c|c|}
\hline FAIXA ETÁRIA & NÜMEO DE RESPOSTAS & PERCENTUAL DE RESPOSTAS \\
\hline Até 20 anos & 40 & $29,85 \%$ \\
\hline $\mathbf{2 0}-\mathbf{3 0}$ anos & $\mathbf{8 5}$ & $\mathbf{6 3 , 4 3} \%$ \\
\hline $31-40$ anos & 5 & $3,73 \%$ \\
\hline $41-50$ anos & 3 & $2,23 \%$ \\
\hline $51-60$ anos & 1 & $0,74 \%$ \\
\hline Mais de 60 anos & 0 & $0 \%$ \\
\hline \multicolumn{2}{|c|}{ Fonte: Autores } \\
\hline
\end{tabular}




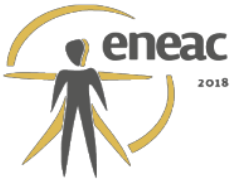

Quanto às opções disponibilizadas que se referiam à existência de deficiência/restrições/mobilidade reduzida, os dados obtidos deixaram evidenciado que a maior parte dos usuários não possui qualquer tipo de deficiência. Outras opções de deficiências/restrições não obtiveram respostas.

Tabela 2. No caso da existência de deficiência/restrição, favor identificá-la.

\begin{tabular}{|c|c|c|}
\hline DEFICIENCIA/RESTRIÇĀO & № DE RESPOSTAS & PERCENTUAL DE RESPOSTAS \\
\hline Def. Visual - Baixa Visão & 4 & $2,98 \%$ \\
\hline Obesidade & 3 & $2,23 \%$ \\
\hline Gestante & 1 & $0,74 \%$ \\
\hline Acomp. de carrinho de bebê & 1 & $0,74 \%$ \\
\hline Nenhuma & $\mathbf{1 2 5}$ & $\mathbf{9 3 , 2 8} \%$ \\
\hline \multicolumn{2}{|c|}{ Fonte: Autores }
\end{tabular}

Para identificar a grande demanda dos espaços atuais, evidenciando a importância desta análise devido ao fluxo de usuários, foi questionado qual a frequência semanal de utilização dos espaços de restaurantes universitários. Para maiores esclarecimentos, também foi questionado quais restaurantes são mais utilizados pela comunidade acadêmica.

Tabela 3. Qual a sua frequência de utilização do RU? Qual RU você mais utiliza?

\begin{tabular}{|c|c|c|c|c|c|}
\hline $\begin{array}{c}\text { FREQUÊNCIA } \\
\text { SEMANAL }\end{array}$ & $\begin{array}{c}\text { No DE } \\
\text { RESP. }\end{array}$ & $\%$ & PRÉDIO & $\begin{array}{c}\text { № DE } \\
\text { RESP. }\end{array}$ & $\%$ \\
\hline Ocasionalmente & 40 & $29,85 \%$ & $\begin{array}{c}\text { Centro - R. Andrades } \\
\text { Neves }\end{array}$ & 31 & $23,13 \%$ \\
\hline 1 a 3 dias & 29 & $21,64 \%$ & $\begin{array}{c}\text { Campus Capão do } \\
\text { Leão }\end{array}$ & 30 & $22,38 \%$ \\
\hline $\mathbf{4}$ a $\mathbf{5}$ dias & $\mathbf{4 5}$ & $\mathbf{3 3 , 5 8 \%}$ & $\begin{array}{c}\text { Centro - R. Quinze de } \\
\text { Novembro }\end{array}$ & $\mathbf{7 3}$ & $\mathbf{5 4 , 4 7 \%}$ \\
\hline 6 a 7 dias & 20 & $14,92 \%$ & - & - & - \\
\hline
\end{tabular}

Fonte: Autores

Coletadas as informações dos usuários, pediu-se percepção dos mesmos para com os ambientes os quais utilizam. Separando as avaliações nos quatro componentes da acessibilidade espacial e dando possibilidade de atribuição de notas que variavam de 1 (muito ruim) a 5 (muito bom), os resultados obtidos mostram, em maioria, a insatisfação dos usuários com os espaços existentes.

Tabela 4. Como você avalia as condições do RU acessado?

\begin{tabular}{|c|c|c|c|}
\hline COMPONENTE & $\begin{array}{c}\text { CONCEITO } \\
\text { PREDOMINANTE }\end{array}$ & $\begin{array}{c}\text { RESPOSTAS } \\
\text { REFERENTES }\end{array}$ & $\begin{array}{c}\text { PERCENTUAL DA } \\
\text { AMOSTRA }\end{array}$ \\
\hline Deslocamento & 3-Mediano & 58 & $43,28 \%$ \\
\hline $\begin{array}{c}\text { Orientação } \\
\text { Espacial }\end{array}$ & 2 - Ruim & 51 & $38,05 \%$ \\
\hline Uso & 3- Mediano & 47 & $35,07 \%$ \\
\hline Comunicação & $\begin{array}{c}\text { 1- Muito } \\
\text { ruim }\end{array}$ & 65 & $\mathbf{4 8 , 5 0 \%}$ \\
\hline
\end{tabular}

Fonte: Autores. 
Após as perguntas obrigatórias, deixou-se um espaço livre para expressão de opiniões que envolvessem acessibilidade e ergonomia, sendo algumas expostas a seguir:

Tabela 5. Opiniões livres dos usuários.

\begin{tabular}{|c|c|}
\hline $\begin{array}{l}\text { "O espaço no RU não é muito fácil de se } \\
\text { locomover e acaba sendo desconfortável } \\
\text { para quem não tem nenhuma restrição, } \\
\text { imagino a alguém que possui essas } \\
\text { restrições." }\end{array}$ & $\begin{array}{l}\text { "Dificuldade de locomoção entre as mesas } \\
\text { mesmo para pessoas sem deficiência, pelo } \\
\text { espaço apertado; Piso escorregadio; } \\
\text { Passagens apertadas (na entrada, ao } \\
\text { mostrar a identificação); } \\
\text { desorganizadas e que mudam } \\
\text { frequentemente de padrão (o que confunde } \\
\text { as pessoas que utilizam o restaurante)." }\end{array}$ \\
\hline $\begin{array}{l}\text { "Os bancos são muito pequenos e há pouco } \\
\text { espaço entre eles, não há circulação entre } \\
\text { as mesas (entre os usuários que estão } \\
\text { sentados). A maioria dos estudantes } \\
\text { carrega sempre muito material e não há } \\
\text { local para deixá-lo durante o almoço, sendo } \\
\text { difícil até servir a comida. A rampa metálica } \\
\text { é super perigosa até mesmo para mim, que } \\
\text { não possuo qualquer deficiência." }\end{array}$ & $\begin{array}{l}\text { "Eu tenho plenas condições de utilizar o } \\
\text { espaço pois não tenho nenhuma limitação } \\
\text { física e já conheço o lugar (frequento há } 4 \\
\text { anos), no entanto quem não conhece deve } \\
\text { sentir muita dificuldade de encontrar pois } \\
\text { não tem placas de informação e aos que } \\
\text { possuem necessidade especial, então, o } \\
\text { local é muito despreparado." }\end{array}$ \\
\hline
\end{tabular}

Fonte: Autores.

Tendo em vista os dados coletados, entende-se a importância de investigar o projeto do restaurante universitário para que sejam feitas as intervenções necessárias, revertendo os atuais índices de insatisfação quando a obra for concluída.

\subsection{Entrevista integrada e pesquisa focal}

Observando a predominância de pessoas sem quaisquer deficiências no questionário geral, entende-se a necessidade do estudo focal, através de entrevista integrada, acerca das percepções das pessoas com deficiência que utilizem o RU. Com apoio do Núcleo de Acessibilidade e Inclusão (NAI), foi desenvolvido tal estudo, o qual juntamente com o questionário, configura o que este trabalho chama de pesquisa integrada. Essa técnica contempla o contato direto com pessoas com deficiência ou restrição da Universidade para dar visibilidade às suas demandas específicas. O foco é identificar se a existência de deficiências/restrições é um fator determinante para impedimento do uso dos espaços de $\mathrm{RU}$ já que, de acordo com o NAI, em quase 49 anos de história de UFPel, nunca foi feita uma pesquisa de percepção e satisfação dos usuários com deficiência ou restrição, sejam alunos ou servidores, fato que torna este trabalho de pesquisa pioneiro com a abordagem.

Visto que é fundamental dar visibilidade às demandas de tais pessoas para a promoção da inclusão, a apresentação do trabalho e o convite para tal entrevista contou com publicação de vídeo interpretado em LIBRAS, contatos por e-mail e telefone, objetivando respostas para quatro perguntas simples, porém fundamentalmente importantes para a garantia de um espaço inclusivo: 1) Utiliza os serviços de algum dos atuais Restaurantes-Escola?; 2) Se 


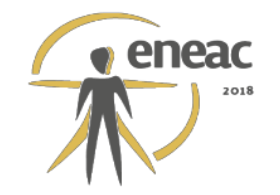

não utiliza, há algum motivo especificamente vinculado às questões de acessibilidade neste ambiente acadêmico?; 3) Se você utiliza, há alguma condição restritiva ou impeditiva, de acordo com as questões de acessibilidade?; 4) Existe alguma demanda que deseja salientar, especificamente envolvendo questões de acessibilidade e ergonomia? Ademais, é deixada a oportunidade para pautas que não são diretamente vinculadas à pesquisa, sendo todos os seus resultados apresentados no evento.

Figura 1. Convite online para entrevista integrada. Versão em LIBRAS.

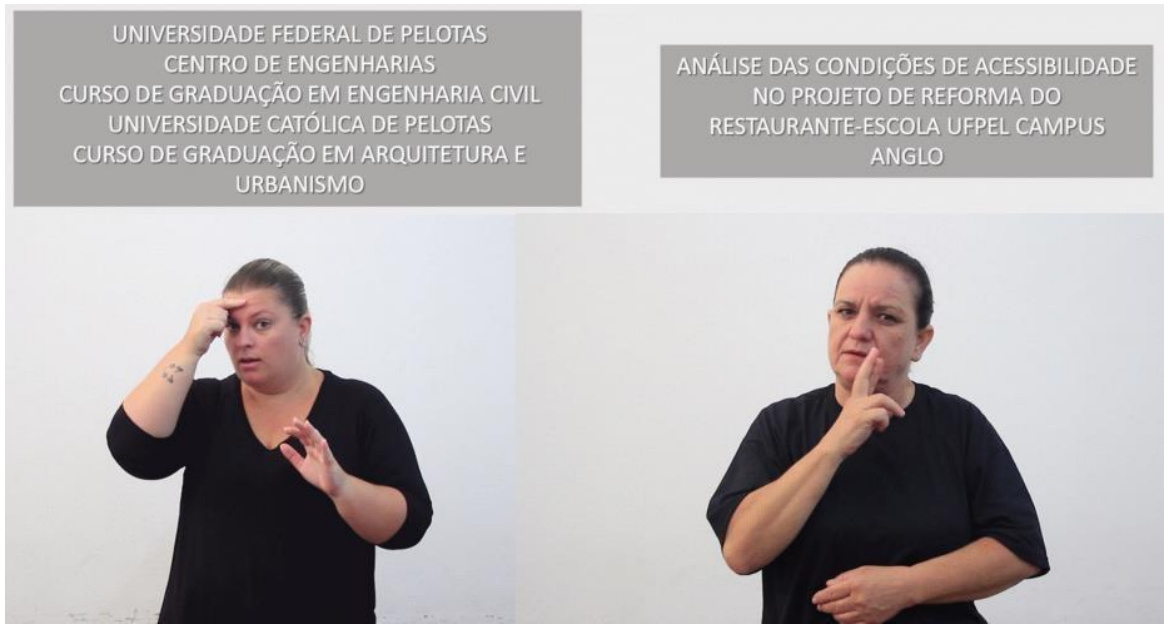

Fonte: Autores, com apoio do NAI UFPel.

\subsection{Perícia projetual e laudo técnico-acadêmico}

Utilizando o modelo de avaliação em ambientes construídos, disponível em Promovendo acessibilidade espacial nos edifícios públicos (DISCHINGER, BINS ELY E PIARDI, 2012) e as bibliografias descritas no item 4.1, pode-se executar perícia projetual dos espaços, mobiliários e também elaborar laudo técnico-acadêmico, disposto em material à parte, porém transcrito na tabela abaixo.

Tabela 6. Laudo técnico-acadêmico.

\begin{tabular}{|c|c|c|}
\hline PROBLEMÁTICA & INTERVENÇÃO & EMBASAMENTO \\
\hline $\begin{array}{c}\text { Inexistência de faixa de } \\
\text { pedestres próxima à via } \\
\text { carroçável }\end{array}$ & $\begin{array}{c}\text { Pintura de faixa de } \\
\text { pedestres ao fim da guia } \\
\text { rebaixada }\end{array}$ & $\begin{array}{c}\text { NBR 9050/2015 } \\
\text { (item 6.12.7) }\end{array}$ \\
\hline $\begin{array}{c}\text { Passeio com piso irregular, } \\
\text { sendo a pavimentação } \\
\text { licitada descontínua entre o } \\
\text { acesso da Universidade e o } \\
\text { acesso do RU (Ver Fig. 2) }\end{array}$ & $\begin{array}{c}\text { Prolongamento da calçada } \\
\text { de concreto }\end{array}$ & NBR 9050/2015 (item 6.3.2) \\
\hline $\begin{array}{c}\text { Inconformidades e } \\
\text { descontinuidade nos pisos } \\
\text { táteis no passeio }\end{array}$ & $\begin{array}{c}\text { Correção da sinalização e } \\
\text { prolongamento da } \\
\text { colocação de pisos táteis }\end{array}$ & NBR 16.537/2016 \\
\hline $\begin{array}{c}\text { Inexistência de vagas de } \\
\text { estacionamento prioritárias }\end{array}$ & $\begin{array}{c}\text { Previsão de vagas } \\
\text { prioritárias em 2\% do total }\end{array}$ & $\begin{array}{c}\text { Decreto Federal 5.296/2004 } \\
\text { (Art. 25) }\end{array}$ \\
\hline Inexistência de faixas de & Aplicação de faixas visíveis & NBR 9050/2015 \\
\hline
\end{tabular}




\begin{tabular}{|c|c|c|}
\hline visor para portas de vidro & com dimensões mínimas & (item 6.11.2.13) \\
\hline $\begin{array}{l}\text { Não há previsão de fila } \\
\text { preferencial ou atendimento } \\
\text { prioritário }\end{array}$ & $\begin{array}{c}\text { Prioritários deverão ter } \\
\text { acesso imediato aos } \\
\text { serviços }\end{array}$ & $\begin{array}{l}\text { Lei Federal 10.048/2000 } \\
\text { (Art 1ํ) }\end{array}$ \\
\hline $\begin{array}{l}\text { Não há identificação de } \\
\text { assentos preferenciais }\end{array}$ & $\begin{array}{c}\text { Adesivamento de } \\
\text { pictogramas nos espaços } \\
\text { preferenciais }\end{array}$ & $\begin{array}{l}\text { Decreto Federal 5.296/2004 } \\
\quad \text { (Art. 6oㅗ } \S 1^{\circ} \text {, inc. I) }\end{array}$ \\
\hline $\begin{array}{l}\text { Não há previsão de } \\
\text { atendimento em LIBRAS }\end{array}$ & $\begin{array}{l}\text { A contratada pelos serviços } \\
\text { de restaurante deverá } \\
\text { dispor de um intérprete }\end{array}$ & $\begin{array}{l}\text { Decreto Federal 5.296/2004 } \\
\quad \text { (Art. 6º, § 1ํ, inc. III) }\end{array}$ \\
\hline $\begin{array}{c}\text { Não há previsão de } \\
\text { disponibilização de cardápio } \\
\text { em Braille }\end{array}$ & $\begin{array}{c}\text { A contratada deverá } \\
\text { disponibilizar diariamente } \\
\text { cardápio em Braille e com } \\
\text { caracteres ampliados }\end{array}$ & $\begin{array}{l}\text { NBR } 9050 / 2015 \\
\text { (item 10.8.2.3) }\end{array}$ \\
\hline $\begin{array}{l}\text { Guichês de caixas não } \\
\text { possuem recuo para } \\
\text { aproximação de PCRs }\end{array}$ & $\begin{array}{l}\text { Adaptação no mobiliário } \\
\text { com recuo }\end{array}$ & $\begin{array}{l}\text { NBR } 9050 / 2015 \\
\text { (item 9.2.1.5) }\end{array}$ \\
\hline $\begin{array}{l}\text { Mesas para refeições têm } \\
\text { tampo com largura de } 80 \mathrm{~cm}\end{array}$ & $\begin{array}{c}\text { Espaço de aproximação é } \\
\text { garantido a PCRs mediante } \\
\text { redução do espaço útil para } \\
\text { usuários à frente }\end{array}$ & $\begin{array}{c}\text { Não atende à NBR } \\
\text { 9050/2015 (item 9.3.1.3) } \\
\text { porém atende ao mínimo } \\
\text { em Panero e Zelnik } \\
\text { (cap. 5.3) }\end{array}$ \\
\hline $\begin{array}{l}\text { Não existe previsão de } \\
\text { assento destinado a obesos. } \\
\text { Largura licitada em } 42 \mathrm{~cm} \text { e } \\
\text { suporte para } 140 \mathrm{Kg} .\end{array}$ & $\begin{array}{l}\text { Colocação temporária de } \\
\text { cadeira específica nos } \\
\text { espaços reservados a PCRs }\end{array}$ & $\begin{array}{c}\text { Licitado não atende à NBR } \\
\text { 9050/2015 (itens 4.7.1 e } \\
\text { 4.7.2) porém atende aos } \\
\text { mínimos em Panero e Zelnik } \\
\text { (cap. 1) }\end{array}$ \\
\hline $\begin{array}{l}\text { Pisos serão em granitina, } \\
\text { considerada derrapante. }\end{array}$ & $\begin{array}{l}\text { Tratamento antiderrapante } \\
\text { para pisos }\end{array}$ & $\begin{array}{l}\text { NBR } 9050 / 2015 \\
\text { (item 6.3.2) }\end{array}$ \\
\hline $\begin{array}{l}\text { Não há puxador na porta } \\
\text { dos banheiros acessíveis }\end{array}$ & $\begin{array}{l}\text { Instalação de puxador de no } \\
\text { mínimo } 40 \mathrm{~cm}\end{array}$ & $\begin{array}{l}\text { NBR 9050/2015 } \\
\text { (item 6.11.2.7) }\end{array}$ \\
\hline $\begin{array}{c}\text { Barras de apoio inexistentes } \\
\text { ou inadequadas }\end{array}$ & $\begin{array}{c}\text { Instalação das barras } \\
\text { conforme casos específicos }\end{array}$ & $\begin{array}{c}\text { NBR } 9050 / 2015 \text { (itens } \\
7.7 .2 .3 .3,7.8 .1 \text { e } 7.10 .4 .3 \text { ) }\end{array}$ \\
\hline $\begin{array}{l}\text { Sanitários comuns não } \\
\text { possuem espaçamentos e } \\
\text { vãos adequados } \\
\text { (Ver Fig. 3) }\end{array}$ & $\begin{array}{c}\text { Adaptação das divisórias e } \\
\text { aberturas }\end{array}$ & $\begin{array}{l}\text { NBR } 9050 / 2015 \\
\text { (item 7.10.1) }\end{array}$ \\
\hline $\begin{array}{l}\text { Alguns deslocamentos não } \\
\text { permitem manobra de PCRs } \\
\text { (entrada sanitários e espaço } \\
\text { de lixeiras) }\end{array}$ & $\begin{array}{c}\text { Adaptação de divisórias } \\
\text { para devido espaçamento } \\
\text { (Ver Fig. 4) }\end{array}$ & $\begin{array}{l}\text { NBR } 9050 / 2015 \\
\quad \text { (item 4.3.5) }\end{array}$ \\
\hline $\begin{array}{l}\text { Percentual de mesas } \\
\text { acessíveis a PCRs está } \\
\text { inadequado }\end{array}$ & $\begin{array}{c}\text { Garantia de no mínimo } 5 \\
\text { mesas acessíveis }\end{array}$ & $\begin{array}{l}\text { NBR } 9050 / 2015 \\
\text { (item 10.8.1) }\end{array}$ \\
\hline $\begin{array}{c}\text { Altura dos buffets e módulos } \\
\text { de tempero, frutas e } \\
\text { talheres excede o limite, } \\
\text { tendo } 91 \mathrm{~cm}\end{array}$ & $\begin{array}{c}\text { A contratada deverá } \\
\text { disponibilizar funcionário } \\
\text { para dar assistência nos } \\
\text { buffets }\end{array}$ & $\begin{array}{c}\text { Não respeita NBR } \\
\text { 9050/2015 (item 9.3.3.3) }\end{array}$ \\
\hline $\begin{array}{c}\text { Lixeiras têm abertura } \\
\text { acionada por pedal, } \\
\text { desconhece-se altura do } \\
\text { passa-pratos }\end{array}$ & $\begin{array}{l}\text { Remoção das tampas das } \\
\text { lixeiras e respeitar alturas } \\
\text { máximas para alcance }\end{array}$ & $\begin{array}{l}\text { NBR } 9050 / 2015 \\
\text { (item 4.6.2) }\end{array}$ \\
\hline
\end{tabular}

Fonte: Autores. 


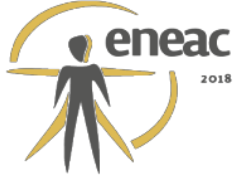

Figura 2. Calçada de acesso ao futuro RU, onde não é prevista pavimentação contínua.

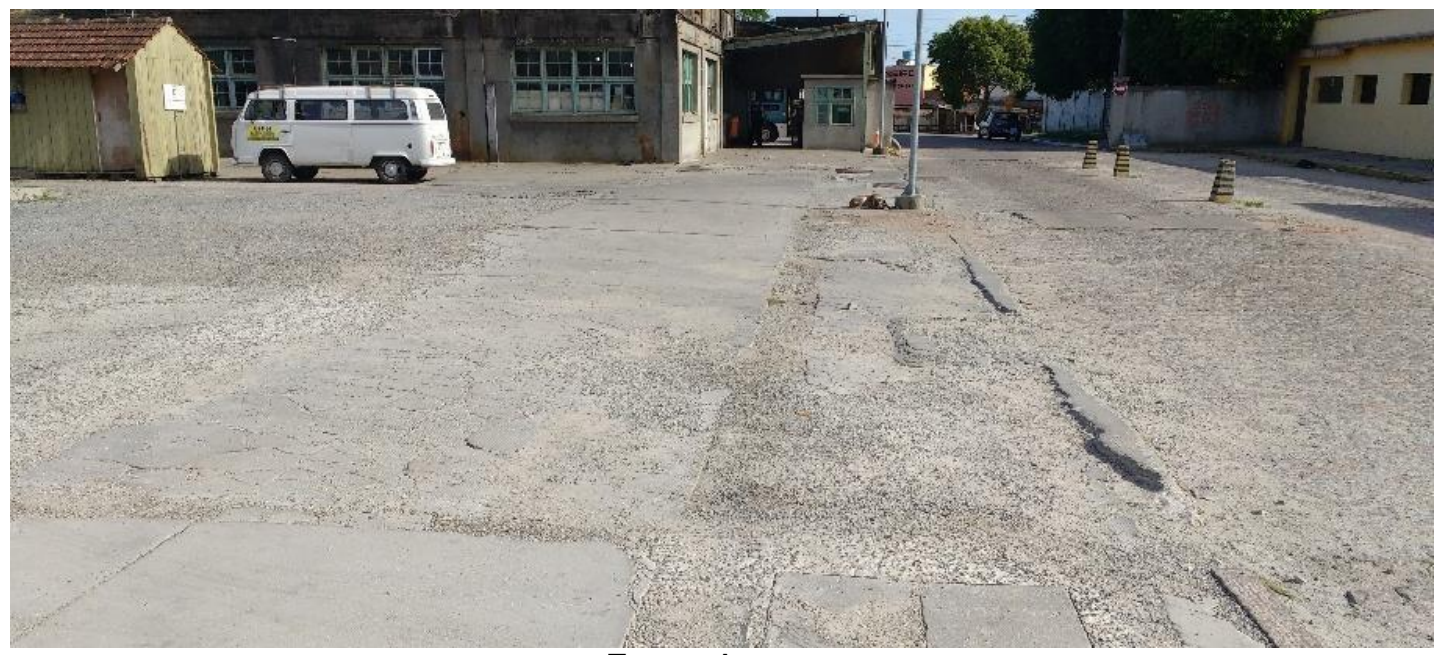

Fonte: Autores.

Figura 3. Espaçamentos insuficientes de box comum e o mínimo por norma.

\section{PROJETO LICITADO}
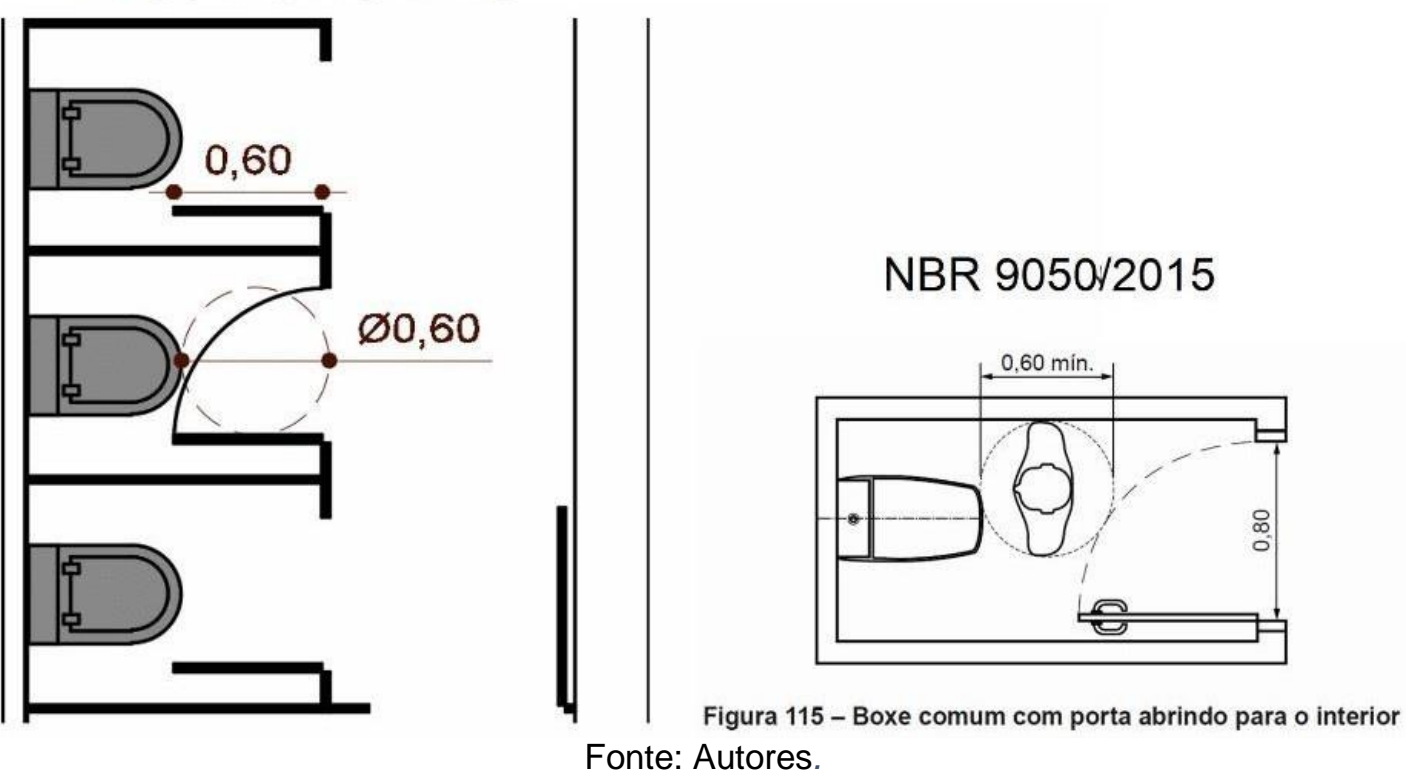

Devido à limitação de páginas, todas as demais problemáticas do laudo técnico-acadêmico serão apresentadas visualmente no evento, bem como suas propostas de intervenção.

\subsection{Propostas gráficas de intervenção}

Entendendo a importância de recursos gráficos para a visualização e compreensão das propostas intervencionistas, este trabalho conta com o desenvolvimento de projeto em planta baixa e em maquete eletrônica por fotorrealismo ainda em andamento. Todas as tomadas de decisões seguem o laudo técnico-acadêmico e serão divulgados publicamente, sendo o modelo a seguir um exemplo. 


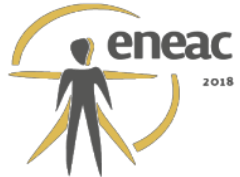

Figura 4. Modelo de proposta de intervenção projetual.

PROJETO LICITADO

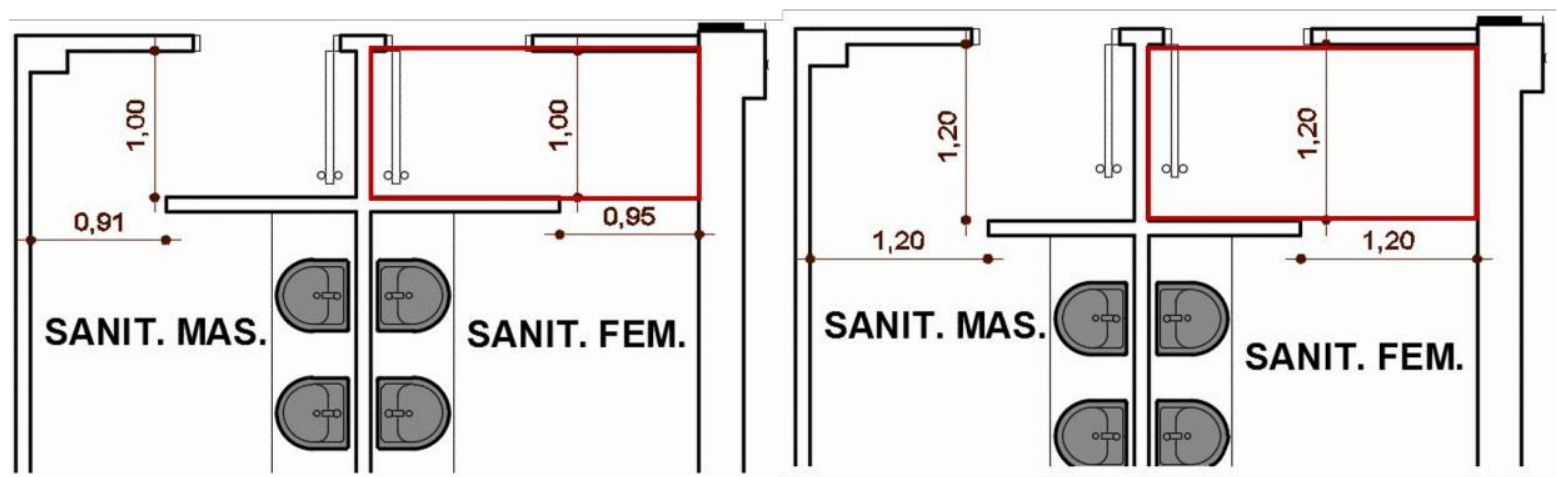

Fonte: Autores.

Todos os demais modelos em planta baixa e imagens fotorrealistas serão apresentadas como resultados no evento em questão devido à limitação de páginas.

\section{CONCLUSÃO}

Por tratar-se de um trabalho ainda em desenvolvimento nas etapas de pesquisa e intervenções projetuais, o número de perdas de assentos para refeições ainda não pode ser estabelecido, embora não sejam previstas quaisquer perdas nas soluções propostas. Baseando-se nas bibliografias, nas normas e legislações vigentes, foi estabelecido um roteiro investigativo que já deixa exposto para a Administração da Universidade quais as problemáticas que imediatamente devem ser solucionadas, bem como todo o referencial teórico que comprova a necessidade de aplicar tais soluções. Ademais, está sendo feita grande mobilização acerca da pesquisa integrada deste trabalho, já que conta participação inclusiva de pessoas com deficiência, mediante contato direto e comunicação acessível.

A acessibilidade não pode ser considerada um privilégio, mas sim um elemento fundamental para o desenvolvimento social, já que envolve muito mais variáveis que apenas a existência ou inexistência de deficiência. É fundamental que sejam previstos estudos, aplicações e fiscalização nos processos para promover acessibilidade, para que assim os espaços públicos possam contar com participação inclusiva, respeitando a diversidade e garantindo o dinamismo que engloba toda a configuração humana. É através deste material que deixa-se uma contribuição à Universidade Federal de Pelotas, para que todos possam desfrutar de um espaço de convivência não apenas agradável e eficaz, mas sim eficiente. Este trabalho será plenamente divulgado e disporá de espaço para críticas e apontamentos de melhorias, pois, tratando-se de acessibilidade e inclusão, nada é acessível o suficiente que não possa ser melhorado.

\section{REFERÊNCIAS BIBLIOGRÁFICAS}

ASSOCIAÇÃO BRASILEIRA DE NORMAS TÉCNICAS (ABNT). NBR 9050: Acessibilidade a edificações, mobiliário, espaços e equipamentos urbanos. Rio de Janeiro, 2015.

ASSOCIAÇÃO BRASILEIRA DE NORMAS TÉCNICAS (ABNT). NBR 16537: Acessibilidade Sinalização tátil no piso - Diretrizes para elaboração de projetos e instalação. Rio de Janeiro, 2016.

ARAÚJO, Carolina Dutra de; CÂNDIDO, Débora Regina Campos Cândido; LEITE, Márvio Fonseca 


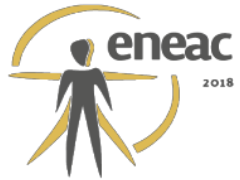

Leite. Espaços públicos de lazer: um olhar sobre a acessibilidade para portadores de necessidades especiais. Licere (Online),v. 12, n. 4, dez. 2009. Disponível em:

$<$ http://www.ufpb.br/cia/contents/relatorios/relatorio-tecnico-do-campus-ii-areia-referente-a-2015.pdf>.

Acesso em: 04 de Fevereiro de 2018.

BRASIL. Constituição da República Federativa do Brasil de 1988. Brasília, 1988. Disponível em: $<$ http://www.planalto.gov.br/ccivil 03/constituicao/constituicao.htm>. Acesso em: 04 de Fevereiro de 2018.

BRASIL. Decreto no 5.296 de 2 de Dezembro de 2004: Regulamenta as Leis nos 10.048 , de 8 de novembro de 2000, que dá prioridade de atendimento às pessoas que especifica, e 10.098, de 19 de dezembro de 2000, que estabelece normas gerais e critérios básicos para a promoção da acessibilidade das pessoas portadoras de deficiência ou com mobilidade reduzida, e dá outras providências. Brasília, 2004. Disponível em: <http://www.planalto.gov.br/ccivil 03/ ato20042006/2004/decreto/d5296.htm>. Acesso em: 04 de Fevereiro de 2018.

BRASIL. Lei no 10.048 de 8 de Novembro de 2000: Dá prioridade de atendimento às pessoas que especifica, e dá outras providências. Brasília, 2000. Disponível em: $<$ http://www.planalto.gov.br/ccivil 03/Leis/L10048.htm>. Acesso em: 04 de Fevereiro de 2018.

BRASIL. Lei no 8.666 de 21 de Junho de 1993: Regulamenta o art. 37, inciso XXI, da Constituição Federal, institui normas para licitações e contratos da Administração Pública e dá outras providências. Brasília, 1993. Disponível em: <http://www.planalto.gov.br/ccivil 03/Leis/L8666cons.htm>. Acesso em: 04 de Fevereiro de 2018.

DISCHINGER, Marta; PIARDI, Sonia Maria; BINS ELY, Vera Helena. Promovendo acessibilidade espacial nos edifícios públicos: Programa de Acessibilidade às Pessoas com Deficiência ou Mobilidade Reduzida nas Edificações de Uso Público. MPSC. Florianópolis, 2012.

DUARTE, Cristiane Rose de Siqueira; COHEN, R. Acessibilidade aos Espaços do Ensino e Pesquisa: Desenho Universal na UFRJ - Possível ou Utópico? In: NUTAU 2004: Demandas Sociais, Inovações Tecnológicas e a Cidade, 2004, Sâo Paulo. Anais NUTAU 2004: Demandas Sociais, Inovações Tecnológicas e a Cidade, 2004. Disponível em:

$<$ http://inclusao.coppetec.coppe.ufri.br/documentosnoticias/Acessibilidade aos Espacos de Ensino Publico.pdf >. Acesso em: 04 de Fevereiro de 2018.

MAZZONI, Alberto Angel; TORRES, Elisabeth Fátima; OLIVEIRA, Rúbia; BINS ELY, Vera Helena; ALVES, João Bosco. Aspectos que interferem na construção da acessibilidade em bibliotecas universitárias. Ci. Inf., Brasília, v. 30, n. 2, p. 29-34, 2001. Disponível em:

$<$ http://www.scielo.br/pdf/ci/v30n2/6209 > . Acesso em: 04 de Fevereiro de 2018.

NEUFERT, Ernst. Arte de Projetar em Arquitetura. Barcelona, 2013.

PANERO, Julius; ZELNIK Martin. Dimensionamento humano para espaços interiores. Barcelona, 2002. 